\title{
Analisis Pembiayaan Program Promotif dan Preventif Pemberantasan Demam Berdarah Dengue (DBD) Bersumber Pemerintah di Kota Semarang Tahun 2013-2015
}

\author{
Financing Study on Dengue Preventive Program by Government Source In Semarang, \\ 2013-2015
}

\author{
Nisa Kamila ${ }^{1}$ Mardiati Nadjib² \\ ${ }^{1}$ Program Magister IImu Kesehatan Masyarakat, Fakultas Kesehatan Masyarakat, Universitas Indonesia, Depok \\ ${ }^{2}$ Departemen Administrasi dan Kebijakan Kesehatan, Fakultas Kesehatan Masyarakat, Universitas Indonesia, Depok \\ Korespondensi: Nisa Kamila, \\ e-mail: nisakamila07@gmail.com
}

\begin{abstract}
Abstrak
Selama tahun 2010-2014, Kota Semarang selalu termasuk dalam peringkat tiga besar Incidence Rate Deman Berdarah Dengue (DBD) di Provinsi Jawa Tengah. Penelitian ini bertujuan menganalisis pembiayaan program pemberantasan DBD bersumber pemerintah pada tahun 2013-2015 dan kesenjangan sumberdaya. Pendekatan akun biaya kesehatan (health account) digunakan untuk menelusuri pembiayaan menurut sumber, fungsi, dan penyedia layanan. Hasil studi menunjukkan bahwa total belanja program DBD bersumber APBD tahun 2013 adalah Rp. 4.018.927.020,- meningkat sebesar 101\% pada tahun 2014 dan meningkat sebesar 218\% pada tahun 2015. Belanja terbesar pada program pemberantasan DBD adalah untuk kegiatan surveilans epidemiologi dan pengendalian penyakit menular. Tidak terdapat kesenjangan antara ketersediaan sumber daya (berdasarkan belanja kesehatan program pemberantasan DBD) dengan kebutuhan program (berdasarkan perhitungan kebutuhan metode SPM). Disarankan agar perencanaan program lebih berfokus pada kegiatan promotif dan preventif.

Kata Kunci: Pembiayaan; Program promotif dan preventif; DBD
\end{abstract}

\begin{abstract}
In 2010-2014, Semarang was involved as the big three city with high incidence rate of dengue in Central Java province. This study aimed to analyze the financing by the local government for Dengue preventive program in 2013-2015, as well as the resources gap. The health account approach was used to analyze spending by source, function, and provider. Total local government spending for dengue in 2013 were IDR 4.018.927.020,- increased by 101\% in 2014 and increased by $218 \%$ in 2015. The largest expenditure for Dengue Preventive program is epidemiological surveillance and infectious disease control. There was no gap between available resources and requires program according to SPM. The study suggested to improve planning by focusing on the direct activities such as promotive and preventive.

Keyword: Financing; Promotive and Preventive Program; Dengue
\end{abstract}

\section{Pendahuluan}

Berdasarkan data WHO, Indonesia termasuk kategori A endemik Demam Berdarah Dengue (DBD) yang artinya Indonesia termasuk kategori cukup bahaya DBD (WHOa, 2011), tak terkecuali Jawa Tengah. Incidence Rate (IR) DBD di Provinsi Jawa Tengah pada tahun 2014 sebesar 36,2/100.000 penduduk (Profil Kesehatan Provinsi Jawa Tengah tahun 2015). Hal ini berarti IR DBD di Jawa Tengah lebih rendah dari target nasional yaitu $\leq 51$ per 100 ribu penduduk (Kementerian Kesehatan, 2013).

Dari tahun 2010 - 2014, Kota Semarang selalu menduduki peringkat tiga besar IR DBD di Provinsi Jawa Tengah. IR DBD tertinggi juga terjadi pada tahun 2010 yaitu 368,7 per 100.000 dan Case Fatality Rate (CFR) tertinggi pada tahun 2006 yaitu 2,28\%. IR DBD Kota Semarang dari tahun 2006 - 2014 selalu jauh lebih tinggi dari
IR DBD Provinsi Jawa Tengah dan IR DBD Nasional (Dinas Kesehatan Kota Semarang, 2015).

Undang-Undang No. 36 Tahun 2009 tentang Kesehatan menyatakan bahwa pembiayaan kesehatan bertujuan untuk menyediakan pembiayaan yang berkesinambungan dengan jumlah yang mencukupi, teralokasi secara adil, dan termanfaatkan secara berhasil guna dan berdaya guna untuk menjamin terselenggaranya pembangunan kesehatan agar meningkatkan derajat kesehatan masyarakat setinggi-tingginya. Salah satu kerangka kerja atau alat dalam penyajian pembiayaan kesehatan yang dikeluarkan oleh WHO adalah health accounts. Health accounts menyediakan deskripsi sistematik dari arus keuangan atas konsumsi barang dan pelayanan kesehatan serta bertujuan untuk menjelaskan sistem kesehatan dari perspektif beban pengeluaran (WHOb, 2011). 
Prioritas utama health accounts adalah untuk menyusun data yang handal dan tepat waktu yang dapat dibandingkan antar negara dan antar waktu. Hal ini dibutuhkan untuk melacak tren dalam pengeluaran kesehatan dan faktor pendorongnya, sebagai perbandingan antar negara dan untuk meramalkan pengeluaran kesehatan di masa yang akan datang. Oleh karena itu, penelitian ini bertujuan untuk menganalisis kesenjangan antara kebutuhan anggaran dengan belanja kesehatan program promotif dan preventif pemberantasan DBD di Kota Semarang Tahun 2013-2015.

\section{Metodologi Penelitian}

Penelitian ini menggunakan pendekatan kuantitatif deskriptif dengan metode cross sectional dan pendekatan kualitatif dengan wawancara. Analisis kuantitatif dilakukan untuk membandingkan pembiayaan kesehatan program DBD di Dinas Kesehatan Kota Semarang pada tahun 2013-2015 dengan kebutuhan dana kesehatan. Perbandingan dilakukan untuk melihat ketersediaan dana apakah sudah sesuai dengan kebutuhan dana program DBD.

Pendekatan kualitatif dilakukan dengan cara wawancara mendalam dengan para pengambil kebijakan yaitu Kepala Bidang Pemberantasan dan Pencegahan Penyakit (P2P), Kepala Seksi Pemberantasan Penyakit Bersumber Binatang (P2B2), Kepala Dinas Kesehatan Kota Semarang, dan Anggota DPRD Komisi D yang membawahi bidang kesejahteraan sosial (pendidikan, kesehatan, dan sosial). Data primer dari wawancara mendalam dianalisis dengan cara mengelompokkan, membuat matrik dan menginterpretasikan ke dalam tema penting (Harmana, 2006). Metode triangulasi (sumber dan metode) juga dilakukan untuk mendapatkan analisis data yang valid dan mendapatkan gambaran dari fenoma yang sedang diteliti (Wibowo, 2014).

Dokumen keuangan yang digunakan adalah dokumen realisasi, buku kas umum BPP, data indikator sasaran, Standar Satuan Harga dan Profil Kesehatan Kota Semarang dari Dinas Kesehatan Kota Semarang tahun 2013-2015. Instrumen penelitian untuk mengolah data keuangan menjadi data pembiayaan adalah template health account. Template Standar Pelayanan Minimal (SPM) digunakan untuk menghitung kebutuhan pembiayaan kesehatan di daerah (Sunarjadi, 2007).

\section{Hasil}

Anggaran program pencegahan penularan penyakit endemik/epidemik dan penanggulangan Kejadian Luar Biasa (KLB) Bidang Kesehatan dikelola oleh
Seksi P2B2. 95\% anggaran program pencegahan penularan penyakit endemik/epidemik digunakan untuk program pemberantasan DBD dan sisanya (5\%) untuk penyakit menular bersumber binatang lainnya seperti leptospirosis, chikungunya, malaria, dll. Anggaran pemberdayaan masyarakat di bidang kesehatan dikelola oleh seksi pemberdayaan dan pembiayaan kesehatan, sedangkan anggaran pengadaan alat promosi kesehatan dikelola oleh seksi promosi kesehatan informasi kesehatan. Adapun anggaran gaji dikelola oleh Sub. Kepegawaian.

Anggaran penanggulangan Kejadian Luar Biasa (KLB) bidang kesehatan tahun 2013 dan tahun 2015 lebih sering digunakan untuk penyakit leptospirosis, chikungunya, filariasis, dugaan flu burung dan keracunan makanan. Pada bulan November 2014, ada anggaran sebesar Rp2.600.000 yang digunakan untuk penangan KLB DBD. Dari hasil penelitian di dapatkan bahwa anggaran program pemberdayaan masyarakat bidang kesehatan dikelola oleh seksi Pemberdayaan Pembiayaan Kesehatan (PPK) dan Pengadaan alat promosi kesehatan dikelola oleh seksi Promosi Kesehatan dan Informasi Kesehatan (Promkes Infokes).

Seluruh anggaran untuk program pemberantasan DBD berasal dari APBD Kota Semarang, hanya bantuan berupa alat fogging pada Tahun 2015 sebesar Rp368.000.000 saja yang diperoleh dari APBN (Tabel 1). Dari hasil wawancara mendalam, didapatkan bahwa Dinas Kesehatan Kota Semarang tidak pernah mengajukan untuk pengadaan alat fogging. Alat fogging yang dihibahkan adalah jenis thermal fog merk Swingfog sebanyak 23 buah dengan harga satuan sebesar Rp16.000.000. Dinas Kesehatan Kota Semarang pernah mengajukan dana APBD I untuk insektisida dan larvasida namun tidak diberikan.

Jumlah belanja kesehatan program pemberantasan DBD pada tahun 2013 dan 2014 dikelola oleh Satuan Kerja Perangkat Daerah (SKPD) Dinas Kesehatan Kota. Tahun 2015 sebanyak 95,9\% atau sebesar Rp. 8.521.646.145 dikelola oleh SKPD Dinas Kesehatan Kota dan sisanya sebesar 4,1\% atau sebesar Rp. 368.000.000 dikelola oleh UPT Kementerian Kesehatan lainnya (Tabel 2) yang merupakan hibah fogging dari Kementerian Kesehatan.

Belanja kesehatan program pemberantasan DBD terbesar adalah untuk surveilains epidemiologi dan pengendalian penyakit menular sebesar 49,3\% pada tahun 2013, 48,6\% tahun 2014, dan 73,89\% pada tahun 2015 (Tabel 3). Fungsi surveilains epidemiologi dan pengendalian penyakit menular digunakan untuk kegiatan fogging, pemberantasan sarang nyamuk, penyelidikan epidemiologi, dan lain sebagainya. 
Tabel 1 Belanja kesehatan program DBD tahun 2013-2015 menurut skema pembiayaan

\begin{tabular}{|c|c|c|c|c|c|c|c|}
\hline \multirow[b]{2}{*}{ No } & \multirow{2}{*}{$\begin{array}{c}\text { Skema Pem- } \\
\text { biayaan }\end{array}$} & \multicolumn{6}{|c|}{ Jumlah Belanja (Rp) } \\
\hline & & 2013 & $\begin{array}{l}\text { Persen- } \\
\text { tase }(\%)\end{array}$ & 2014 & $\begin{array}{l}\text { Persen- } \\
\text { tase (\%) }\end{array}$ & 2015 & $\begin{array}{l}\text { Persen- } \\
\text { tase (\%) }\end{array}$ \\
\hline \multirow[b]{2}{*}{1} & HF.1.1.2.2.1 & & & & & & \\
\hline & $\begin{array}{l}\text { APBD Kabupat- } \\
\text { en/Kota }\end{array}$ & 4.018.927.020 & $100,00 \%$ & 4.070.437.985 & $100,00 \%$ & 8.521 .646 .145 & $95,0 \%$ \\
\hline \multirow{3}{*}{2} & HF.1.1.1.1.2 & & & & & & \\
\hline & $\begin{array}{l}\text { APBN Kement- } \\
\text { erian Kesehatan: } \\
\text { Tugas Pemban- } \\
\text { tuan }\end{array}$ & & $0,00 \%$ & & $0,00 \%$ & 368.000 .000 & $4,10 \%$ \\
\hline & Total & 4.018.927.020 & $100,00 \%$ & 4.070 .437 .985 & $100,00 \%$ & 8.889 .646 .145 & $100,00 \%$ \\
\hline
\end{tabular}

Tabel 3 Belanja Kesehatan Program Pemberantasan DBD Tahun 2013-2015 menurut fungsi pelayanan kesehatan

\begin{tabular}{|c|c|c|c|c|c|c|c|}
\hline \multirow[b]{2}{*}{ No } & \multirow{2}{*}{$\begin{array}{l}\text { Fungsi Pelayanan } \\
\text { Kesehatan }\end{array}$} & \multicolumn{6}{|c|}{ Jumlah Belanja (Rp) } \\
\hline & & 2013 & $\begin{array}{l}\text { Persen- } \\
\text { tase (\%) }\end{array}$ & 2014 & $\begin{array}{l}\text { Persen- } \\
\text { tase }(\%)\end{array}$ & 2015 & $\begin{array}{l}\text { Persen- } \\
\text { tase (\%) }\end{array}$ \\
\hline & HC. 6.5 & & & & & & \\
\hline 1 & $\begin{array}{l}\text { Surveilans Epi- } \\
\text { demiologi dan } \\
\text { Pengendalian } \\
\text { Penyakit Menular }\end{array}$ & 1.981 .833 .750 & $49,30 \%$ & 1.979 .676 .865 & $48,60 \%$ & 6.568 .793 .345 & $73,89 \%$ \\
\hline 2 & $\begin{array}{l}\text { HC.7.1 } \\
\text { Tata Kelola dan } \\
\text { Administrasi } \\
\text { Sistem Kesehatan }\end{array}$ & 1.293 .213 .570 & $32,20 \%$ & 1.321 .545 .720 & $32,50 \%$ & 1.538 .782 .100 & $17,31 \%$ \\
\hline 3 & $\begin{array}{l}\text { HC.9.1 } \\
\text { Program Pember- } \\
\text { dayaan Mas- } \\
\text { yarakat }\end{array}$ & 711.967 .200 & $17,70 \%$ & 490.315 .400 & $12,00 \%$ & 545.250 .700 & $6,13 \%$ \\
\hline 4 & $\begin{array}{l}\text { HC.6.1 } \\
\text { Program Konsel- } \\
\text { ing Informasi dan } \\
\text { Edukasi (KIE) }\end{array}$ & 31.912 .500 & $0,80 \%$ & 276.300 .000 & $6,80 \%$ & 228.450 .000 & $2,57 \%$ \\
\hline 5 & $\begin{array}{l}\text { HC.6.6 } \\
\text { Program Kesiapan } \\
\text { Penanganan KLB }\end{array}$ & & $0,00 \%$ & 2.600 .000 & $0,10 \%$ & & $0,00 \%$ \\
\hline 6 & $\begin{array}{l}\text { HC.6.3 } \\
\text { Program Deteksi } \\
\text { Dini Penyakit }\end{array}$ & & & & & 8.370 .000 & $0,90 \%$ \\
\hline & Total & 4.018 .927 .020 & $100,00 \%$ & 4.070 .437 .985 & $100,00 \%$ & 8.889 .646 .145 & $100,00 \%$ \\
\hline
\end{tabular}


Tabel 2 Belanja kesehatan program DBD tahun 2013-2015 menurut pengelola pembiayaan

\begin{tabular}{cccccccc}
\hline \multirow{2}{*}{ No } & Skema Pembiayaan & \multicolumn{6}{c}{ Jumlah Belanja (Rp) } \\
\cline { 2 - 7 } & $\mathbf{2 0 1 3}$ & $\begin{array}{l}\text { Persen- } \\
\text { tase (\%) }\end{array}$ & $\mathbf{2 0 1 4}$ & $\begin{array}{c}\text { Persen- } \\
\text { tase (\%) }\end{array}$ & $\mathbf{2 0 1 5}$ & $\begin{array}{c}\text { Persen- } \\
\text { tase (\%) }\end{array}$ \\
\hline \multirow{2}{*}{$\begin{array}{l}\text { FA.1.2.2.01 } \\
1\end{array}$} & $\begin{array}{l}\text { SKPD Dinas } \\
\text { Kesehatan Kota }\end{array}$ & 4.018 .927 .020 & $100,00 \%$ & 4.070 .437 .985 & $100,00 \%$ & 8.521 .646 .145 & $95,90 \%$ \\
\hline & $\begin{array}{l}\text { FA.1.1.1.9 } \\
\text { UPT Kementerian } \\
\text { Kesehatan lainnya }\end{array}$ & $0,00 \%$ & & $0,00 \%$ & 368.000 .000 & $4,10 \%$ \\
\hline \multicolumn{1}{c}{ Total } & 4.018 .927 .020 & $100,00 \%$ & $4,070,437,985$ & $100,00 \%$ & 8.889 .646 .145 & $100,00 \%$ \\
\hline
\end{tabular}

Tabel 4 Belanja Kesehatan Program Pemberantasan DBD Tahun 2013-2015 menurut kegiatan

\begin{tabular}{lcccc}
\hline \multirow{2}{*}{ Kegiatan } & \multicolumn{2}{c}{2014} & \multicolumn{2}{c}{2015} \\
\cline { 2 - 5 } & Jumlah (Rp) & Persentase (\%) & Jumlah (Rp) & Persentase (\%) \\
\hline Pemeriksaan Jentik Rutin & 874.985 .000 & $45,92 \%$ & 3.249 .330 .900 & $55,42 \%$ \\
Fogging & 324.544 .450 & $17,03 \%$ & 250.153 .480 & $4,27 \%$ \\
Penyelidikan Epidemiologi & 84.300 .000 & $4,42 \%$ & 19.300 .000 & $0,33 \%$ \\
Penemuan dan Pemantauan & 73.000 .000 & $3,83 \%$ & 428.301 .000 & $7,31 \%$ \\
Kasus & 548.443 .715 & $28,79 \%$ & 1.915 .999 .465 & $32,68 \%$ \\
Rest & 1.905 .273 .165 & $100 \%$ & 5.863 .084 .845 & $100 \%$ \\
\hline Total & & &
\end{tabular}

Tabel 5 Belanja Kesehatan Program Pemberantasan DBD Tahun 2013-2015 menurut Penyedia Layanan

\begin{tabular}{|c|c|c|c|c|c|c|c|}
\hline \multirow{2}{*}{ No } & \multirow{2}{*}{$\begin{array}{l}\text { Fungsi Pelayanan } \\
\text { Kesehatan }\end{array}$} & \multicolumn{6}{|c|}{ Jumlah Belanja (Rp) } \\
\hline & & 2013 & $\begin{array}{l}\text { Persen- } \\
\text { tase (\%) }\end{array}$ & 2014 & $\begin{array}{l}\text { Persen- } \\
\text { tase (\%) }\end{array}$ & 2015 & $\begin{array}{l}\text { Persen- } \\
\text { tase (\%) }\end{array}$ \\
\hline & HP.7.1.03 & & & & & & \\
\hline 1 & $\begin{array}{l}\text { Dinas Kesehatan } \\
\text { Kabupaten/Kota }\end{array}$ & 3.056 .722 .770 & $76,1 \%$ & 3.427.891.885 & $84,2 \%$ & 7.503.077.600 & $84,4 \%$ \\
\hline 2 & $\begin{array}{l}\text { HP.6.1.1 } \\
\text { Puskesmas }\end{array}$ & 962.154 .250 & $23,9 \%$ & 642.546 .100 & $15,8 \%$ & 1.321.181.045 & $14,9 \%$ \\
\hline 3 & $\begin{array}{l}\text { HP.6.2.9 } \\
\text { Pelayanan Kese- } \\
\text { hatan oleh mas- } \\
\text { yarakat lainnya }\end{array}$ & - & - & - & - & 39.500 .000 & $0,4 \%$ \\
\hline 4 & $\begin{array}{l}\text { HP.6.2.4 } \\
\text { Puskestren }\end{array}$ & - & - & & & 19.850 .000 & $0,2 \%$ \\
\hline 5 & $\begin{array}{l}\text { HP.6.2.2 } \\
\text { Posyandu }\end{array}$ & & & & & 6.037 .500 & $0,1 \%$ \\
\hline & TOTAL & 4.018.927.020 & $100,00 \%$ & 4.070 .437 .985 & $100,00 \%$ & 8.889 .646 .145 & $100,00 \%$ \\
\hline
\end{tabular}


Anggaran program pemberantasan DBD yang diadakan oleh Dinas Kesehatan Kota Semarang tidak seluruhnya digunakan untuk pelayanan oleh Dinas Kesehatan Kota Semarang melainkan juga digunakan oleh puskesmas untuk kegiatan seperti belanja bahan-bahan medis dan dana untuk kegiatan fogging, pemeriksaan jentik rutin, penyelidikan epidemiologi, dan lain-lain. Kegiatan yang paling banyak menyedot dana adalah pemeriksaan jentik rutin. Pada tahun 2014 dan 2015 fogging sudah tidak menjadi prioritas utama (Tabel 4).

Berdasarkan Tabel 5, belanja kesehatan program pemberantasan DBD yang dikelola oleh puskesmas meningkat pada tahun 2015, namun peningkatan ini tidak sebanding dengan peningkatan persentase alokasi anggaran program pemberantasan DBD yang justru menurun. Hanya di tahun 2015 program pemberantasan DBD juga dilakukan oleh pelayanan kesehatan masyarakat lainnya, pos kesehatan pesantren dan pos pelayanan terpadu.

Perhitungan kebutuhan dengan metode SPM mengacu pada petunjuk teknis penghitungan kebutuhan program pemberantasan DBD dengan
SPM yang terdapat dalam Permekes No. 741 tahun 2008. Hasil perhitungan kebutuhan menggunakan metode SPM didapatkan jumlah kebutuhan anggaran untuk program pemberantasan DBD (Tabel 6).

Untuk melihat kesenjangan belanja kesehatan program pemberantasan $\mathrm{DBD}$, dilakukan analisis berdasarkan perhitungan belanja kesehatan menggunakan SHA 2011 dan perhitungan kebutuhan menggunakan SPM. Dari hasil analisis didapatkan selisih antara total belanja kesehatan dan kebutuhan (Tabel 7).

Berdasarkan tabel 7 dijelaskan bahwa belanja kesehatan Dinas Kesehatan jauh leih besar daripada perhitungan kebutuhan biaya. Pada tahun 2013 belanja Kesehatan hampir 1,6 kali dibandingkan dengan kebutuhan anggaran. Pada tahun 2014 belanja kesehatan juga 1,6 kali lipat dari kebutuhan anggaran. Pada tahun 2015 belanja kesehatan hampir 3,6 kali lipat dibanding kebutuhan anggaran. Dapat dilihat bahwa standar pelayanan minimal untuk program pemberantasan DBD dapat dilaksanakan. Jadi dapat disimpulkan bahwa tidak ada kesenjangan antara perhitungan kebutuhan metode SPM dengan jumlah belanja kesehatan.

Tabel 6. Kebutuhan Anggaran untuk Program Pemberantasan DBD

\begin{tabular}{cc}
\hline Tahun & Kebutuhan Anggaran (Rp) \\
\hline 2013 & $2,522,346,894$ \\
2014 & $2,467,063,291$ \\
2015 & $2,511,488,522$ \\
\hline
\end{tabular}

Tabel 7 Selisih Belanja Kesehatan dengan Kebutuhan Biaya Penanggulangan Penyakit DBD Dinas Kesehatan Kota Semarang Tahun 2013-2015

\begin{tabular}{ccccc}
\hline Tahun & $\begin{array}{c}\text { Belanja Kesehatan } \\
(\mathbf{R p})\end{array}$ & $\begin{array}{c}\text { Kebutuhan Anggaran } \\
(\mathbf{R p})\end{array}$ & Selisih (Rp) & Persentase (Rp) \\
\hline 2013 & $4,018,927,020$ & $2,522,346,894$ & $1,496,580,126$ & $159 \%$ \\
2014 & $4,070,437,985$ & $2,467,063,291$ & $1,603,374,694$ & $165 \%$ \\
2015 & $8,889,646,145$ & $2,511,488,522$ & $6,378,157,623$ & $354 \%$ \\
\hline
\end{tabular}

\section{Pembahasan}

Menurut Jowett (1999) investigasi pengeluaran untuk pelayanan kesehatan nasional berguna sebagai starting point dalam menjawab pertanyaan tentang akses keuangan untuk pelayanan kesehatan, efisiensi alokasi sumber daya,dan keberlangsungan finansial atas pengadaan pelayanan. Dengan menganalisis pembiayaan kesehatan berdasarkan skema pembiayaan, dapat dilihat keberlangsungan finan- sial atas pengadaan pelayanan, analisis berdasarkan fungsi pelayanan kesehatan, efisiensi alokasi sumber daya dan melihat kepada siapa saja dana diberikan untuk menyediakan pelayanan kesehatan.

Perhatian Pemerintah Kota Semarang akan tingginya kasus DBD tercermin dari adanya peningkatan anggaran pemberantasan DBD. Pada tahun 2013 sebesar Rp. 4.932.278.120, tahun 2014 se- 
dikit berkurang menjadi Rp. 4.847.715.020 dan tahun 2015 anggaran naik dua kali lipat menjadi Rp. 11.182.376.100. Dana tersebut 100\% berasal dari APBD Kota Semarang dengan seluruh pengelolaan pembiayaan dilaksanakan oleh SKPD Pemerintah Kota Semarang. Hal ini menunjukkan tingginya tingkat keberlangsungan pembiayaan program pemberantasan DBD karena pembiayaan tidak tergantung dari pemberian dana sumber lain. Menurut Gottret (2006) keberhasilan dalam mengelola sumber finansial dapat berdampak pada jumlah, jenis jasa yang dibeli dan dampaknya terhadap hasil serta biaya kesehatan (efisiensi alokatif). Semakin sustainable dana yang dimiliki program pemberantasan DBD maka diharapkan jumlah dan jenis jasa yang dikonsumsi akan tercukupi sehingga tujuan program dapat tercapai.

Analisis belanja kesehatan program pemberantasan DBD di Kota Semarang menurut fungsi pelayanan kesehatan menunjukkan bahwa alokasi anggaran terbesar digunakan untuk fungsi surveilans epidemiologi dan pengendalian penyakit menular, di mana hal ini dirasa sudah tepat digunakan sebagai fungsi utama pemberantasan DBD. Alokasi terbesar kedua adalah untuk tata kelola dan administrasi sistem kesehatan. Belanja kesehatan terbesar dalam fungsi tata kelola dan administrasi sistem kesehatan adalah untuk pembayaran gaji, sementara alokasi untuk program DBD yang bersifat promotif dan preventif, seperti program pemberdayaan masyarakat, program KIE, program persiapan penanganan KLB dan program deteksi dini penyakit masih mendapat porsi yang lebih kecil. Empat program tersebut merupakan kegiatan kesehatan masyarakat langsung dan justru berperan penting dalam pemberantasan DBD.

Hasil analisis belanja kesehatan menurut fungsi pelayanan kesehatan membuktikan bahwa alokasi anggaran untuk kegiatan administratif kesehatan masih lebih banyak dibandingkan kegiatan kesehatan masyarakat untuk program DBD. Adanya pembiayaan yang besar dalam sistem birokrasi di Dinas Kesehatan Kota Semarang menyebabkan kegagalan untuk melaksanakan kegiatan yang pada akhirnya berdampak pada tidak tercapainya tujuan dari pemberantasan program DBD. Menurut Singh (2008), negara seharusnya memiliki birokrasi yang kompeten dan jelas kewenangannya. Kelemahan pemerintah daerah dalam birokrasi membatasi mereka untuk bertindak walaupun dana tersedia.

Berdasarkan analisis belanja kesehatan, mayoritas penyedia layanan program pemberantasan DBD di Kota Semarang adalah Dinas Kesehatan Kota Semarang. Berdasarkan hasil wawancara mendalam pada fungsi pemberdayaan masyarakat, kegiatan utama yang dilakukan adalah pertemuan dan sosialisasi yang dikerjakan oleh Dinas Kesehatan Kota Semarang. Fungsi yang dilakukan oleh puskesmas hanya surveilans epidemiologi dan pengendalian penyakit menular. Salah satu penyebab sedikitnya layanan yang disediakan oleh puskesmas adalah puskesmas tidak memiliki anggaran sendiri untuk melakukan kegiatan pemberantasan DBD melainkan menggunakan anggaran Dinas Kesehatan Kota Semarang.

Hal ini menggambarkan kurangnya pelimpahan wewenang pelaksanaan program preventif DBD kepada puskesmas. Menurut Perpres No 72 Tahun 2012, salah satu masalah strategis dari reformasi pembiayaan kesehatan adalah terbatasnya dana operasional puskesmas dalam rangka pelaksanaan program dan kegiatan untuk mencapai target Millenium Development Goals (MDG's). Salah satu target MDG's adalah memerangi HIV, malaria, dan penyakit menular lainnya. Oleh karena itu, dalam rangka reformasi pembiayaan kesehatan, puskesmas seharusnya diberikan kesempatan untuk menyusun penganggaran puskesmas dalam melaksanakan program dan kegiatan pemberantasan DBD sehingga lebih banyak fungsi pelayanan kesehatan yang dilakukan oleh puskesmas.

Setiap penyelenggaraan pelayanan publik harus memiliki standar pelayanan dan dipublikasikan sebagai jaminan adanya kepastian bagi penerima pelayanan (Trapsilorati, 2008). Dinas Kesehatan Kota Semarang sudah pernah menerapkan SPM dalam perhitungan kebutuhan anggaran pada tahun 2011, namun karena hasil perhitungan lebih rendah daripada kebutuhan riil pembiayaan Dinas Kesehatan Kota Semarang maka Dinas Kesehatan Kota Semarang tidak menggunakan SPM lagi dalam menghitung kebutuhan anggaran. Kebutuhan anggaran menurut SPM adalah Rp. 2.522.346.894 pada tahun 2013, Rp. 2.467.063.291 pada tahun 2014, dan Rp. 2.511.488.522 pada tahun 2015. Hasil perhitungan ini tidak memasukkan kebutuhan gaji, biaya penyusutan investasi, dan biaya administrasi lainnya.

Berdasarkan perhitungan SPM (Tabel 6), disimpulkan bahwa tidak ada kesenjangan antara perhitungan kebutuhan metode SPM dengan jumlah belanja kesehatan. Namun, template SPM yang digunakan dalam penelitian ini berdasarkan petunjuk teknis (Juknis) SPM untuk program DBD yang harus dilakukan oleh suatu daerah dalam pemberantasan DBD. Daerah seperti Kabupatendi NTT mungkin dapat menggunakan template SPM ini untuk menghitung kebutuhan anggaran untuk memenuhi SPM karena dana yang dimiliki terkadang tidak 
mencukupi untuk memberikan pelayanan yang maksimal. Berbeda dengan Kota Semarang yang merupakan Ibukota Provinsi Jawa Tengah yang memiliki dana lebih banyak dibandingkan dengan NTT.

\section{Kesimpulan dan Saran Kesimpulan}

Total belanja program DBD bersumber APBD tahun 2013 adalah Rp. 4.018.927.020, meningkat sebesar $101 \%$ pada tahun 2014 dan meningkat sebesar 218\% pada tahun 2015. Semua belanja kesehatan hanya berasal dari APBD Kota Semarang, kecuali pada tahun 2015 di mana terdapat hibah alat fogging dari Kementerian Kesehatan. Kebutuhan anggaran menurut SPM adalah Rp. 2.522.346.894 pada tahun 2013, Rp. 2.467.063.291 pada tahun 2014, dan Rp. 2.511.488.522 pada tahun 2015. Anggaran program pemberantasan DBD yang lebih besar daripada perhitungan kebutuhan menunjukkan kecukupan pembiayaan program pemberantas DBD pada tahun2013-2015. Belanja untuk kegiatan administrasi lebih tinggi daripada belanja untuk program promosi kesehatan dan penangan KLB. Tidak terdapat kesenjangan antara ketersediaan sumber daya (berdasarkan belanja kesehatan program pemberantasan DBD) dengan kebutuhan program (berdasarkan perhitungan kebutuhan metode SPM). Saran

Sebaiknya puskesmas memiliki dana untuk program pemberantasan DBD sehingga apabila ada kegiatan yang mendesak, puskesmas dapat mencairkan dana lebih cepat tanpa harus melakukan pengajuan dana terlebih dahulu kepada Dinkes Kota Semarang yang membutuhkan waktu lebih lama. Selain itu, dibutuhkan juga peningkatan anggaran kesehatan untuk program promosi kesehatan dan penanganan KLB DBD.

\section{Daftar Pustaka}

Dinas Kesehatan Kota Semarang. 2015. Profil Kesehatan Kota Semarang Tahun 2014. Semarang: Dinas Kesehatan Kota Semarang

Gottret, Pablo \& Schieber, George. 2006. Helath Financing Revisited. The World Bank, Washington DC.

Harmana, Tisa.2006. Faktor-Faktor yang Mempengaruhi Pembiayaan Kesehatan Daerah Bersumber
Pada Anggaran Pendapatan dan Belanja Daerah Kabupaten Pontianak Tahun 2006, Tesis. Fakultas Kesehatan Masyarakat Universitas Indonesia, Depok.

Jowett, Matthew. 1999. Bucking the trend? Health care expenditures in low-income Countries 1990-1995. International Journal of helath planning and management, York.

Kementerian Kesehatan. 2012. Profil Kesehatan Indonesia Tahun 2012. Jakarta: Kementerian Kesehatan

Kementerian Kesehatan. 2012. Metode Perhitungan Pembiayaan Kesehatan dalam Implementasi SPM di Kabupaten/Kota.Slide.Workshop Perhitungan Biaya Standar Pelayanan Minimal Kabupaten/ Kota di Provinsi Jawa Barat, Bandung 22-24 Oktober 2014.

Republik Indonesia. 2009. Undang Undang Republik Indonesia Nomor 36 Tahun 2009Tentang Kesehatan. Jakarta.

Singh, Nirvikar. 2008. Decentralization and PublicDelivery of Health CareServices in India. Health Affairs, Indianapolis.

Sunarjadi, Dwi. 2007. Analisis Kecukupan Pembiayaan Kesehatan Bersumber Pemerintah di Puskesmas Baradatu Kabupaten Way Kanan Tahun 2006, Tesis. Fakultas Kesehatan Masyarakat Universitas Indonesia, Depok.

Supraptini. 2002. Pengaruh Limbah Industri Terhadap Lingkungan di Indonesia.

Trapsilowati, W dan Sulistyorini, E. 2008. Pelaksanaan Standar Pelayanan Minimal Program Pencegahan dan Pemberantasan Demam Berdarah Dengue di Dinas Kesehatan Kota Semarang. Buletin Penelitian Sistem Kesehatan Vol 11. PKPK-FK UGM.

Wibowo, Adik. 2014. Metodologi Penelitian Praktis Bidang Kesehatan. PT Raja Grafindo Persada. Jakarta

World Health Organizationa. 2011. Comperehensive Guidelines for Prevention and Control of Dengue and Dengue Haemorrhagic Fever Revised and Expanded Version.

World Health Organizationb, OECD, Eurostat. 2011. A system of Health Account. OECD Publishing. 